\title{
JORNALISMO E DIREITOS HUMANOS: POPULAÇÃO EM SITUAÇÃO DE RUA NO RIO DE JANEIRO
}

\author{
Journalism and human rights: \\ Homeless population in Rio de Janeiro \\ Periodismo y derechos humanos: \\ Población en situación de calle en Río de Janeiro
}

Jorge Kanehide Ijuim

Professor do Programa de Pós-graduação em Jornalismo

Universidade Federal de Santa Catarina - UFSC

ijuimjor@gmail.com

Alice Mitika Koshiyama

Professora do Programa de Pós-graduação em Ciências da Comunicação

Escola de Comunicações e Artes da USP almitika@gmail.com

Suzana Rozendo Bortoli

Doutora pelo Pós-graduação em Ciências da Comunicação

Escola de Comunicações e Artes da USP

sukirozendo@hotmail.com

\section{Resumo}

Este artigo traz à discussão o fenômeno da população em situação de rua na cidade do Rio de Janeiro. Com base na discussão sobre Direitos Humanos, Cidadania e Igualdade e diferença, pudemos lançar nosso olhar sobre o comportamento da imprensa diante dessas pessoas. Para apoiar essa reflexão recorremos a Medina (2008), Carvalho (2015), Morin (2001, 2006) e Santos $(1995,2002,2010)$, entre outros. O estudo nos proporcionou a oportunidade para questionar a prática jornalística diante de questões sociais emergentes. Em seguida, analisamos uma amostra de reportagens sobre o tema, publicadas pelos jornais online Extra e $O$ Globo do período 2008-2016. Para tanto, contamos com os recursos da Análise de Conteúdo (BARDIN, 1970) como forma de examinar os conotativos e denotativos que produzem sentido nos discursos. Este esforço nos permitiu inferir que tal população está à margem da sociedade porque lhe são negados seus direitos de cidadãos e, por isso mesmo, não é reconhecida adequadamente pela administração pública e, por consequência, pela população em geral e pela mídia. Setores expressivos da imprensa reproduzem uma cultura de exclusão, segregação e intolerância à população em situação de rua.

Palavras-chave: Jornalismo e Sociedade; Cidadania; Direitos humanos; Igualdade e diferença; População em situação de rua. 


\begin{abstract}
This paper brings to discussion the phenomenon of the homeless population in Rio de Janeiro city. Based on the debate on Human Rights, Citizenship and Equality, and Difference, we were able to look at the behavior of the press towards these people. Medina (2008), Carvalho (2015), Morin (2001, 2006), and Santos (1995, 2002, 2010), among others, were used to support this reflection. We had the opportunity to cast doubts on journalistic practice in the face of emerging social issues. Afterward, we analyzed a sample of articles on the theme, published by online newspapers Extra and O Globo from 2008-2016. For this purpose, the Content Analysis (BARDIN, 1970) resources were used to examine the connotative and denotative that produce meaning in discourses. We concluded that the population is on the fringes of society due to their rights as citizens denied, for this reason, has not been adequately recognized by the public administration and, consequently, by the general population and media. Therefore, significant sectors of the press reproduce a culture of exclusion, segregation, and intolerance to the homeless population.
\end{abstract}

Keywords: Journalism and Society; Citizenship; Human rights; Equality and difference; Homeless Population.

\title{
Resumen
}

Este artículo trae a discusión el fenómeno de la población en situación de calle en la ciudad de Río de Janeiro. Con base en la discusión sobre Derechos Humanos, Ciudadanía e Igualdad y Diferencia, pudimos observar el comportamiento de la prensa frente a estas personas. Para apoyar esta reflexión recurrimos a Medina (2008), Carvalho (2015), Morin (2001, 2006) y Santos (1995, 2002, 2010), entre otros. El estudio nos brindó la oportunidad de cuestionar la práctica periodística frente a los problemas sociales emergentes. Luego analizamos una muestra de artículos sobre el tema, publicados por los ciber periódicos Extra y O Globo de 2008-2016. Para este fin, confiamos en los recursos del Análisis de Contenido (BARDIN, 1970) como una forma de examinar lo connotativo y denotativo que produce significado en los discursos. Este esfuerzo nos ha permitido inferir que esa población está al margen de la sociedad porque se le niegan sus derechos como ciudadanos y, por lo tanto, no está adecuadamente reconocida por la administración pública y, en consecuencia, por la población en general y los medios de comunicación. Sectores importantes de la prensa reproducen una cultura de exclusión, segregación e intolerancia a la población en situación de calle.

Palabras clave: Periodismo y Sociedad; Ciudadanía; Derechos humanos; Igualdad y diferencia; Población en situación de calle.

\section{A POPULAÇÃO EM SITUAÇÃO DE RUA ENQUANTO FENÔMENO SOCIAL}

A crise econômica do Brasil, nos últimos anos, deflagrou inúmeros problemas e agravou alguns outros, já antigos, a exemplo do crescente número de pessoas que vivem em situação de rua. A Pesquisa Nacional de Amostra por Domicílio (PNAD), do IBGE ${ }^{1}$, divulgada em abril, informa que a taxa de desemprego atingiu $13,7 \%$ no primeiro trimestre do

\footnotetext{
${ }^{1}$ Disponível em:

http://www.ibge.gov.br/home/estatistica/pesquisas/pesquisa_resultados.php?id_pesquisa=149
} 
ano, o que equivale ao número surpreendente de 14,2 milhões de pessoas. O aumento dessa população é uma das consequências desses índices revelados pela PNAD.

A edição do dia 12 de julho de 2017 do Profissão Repórter ${ }^{2}$, da Rede Globo, levantou essa questão e apresentou alguns dados alarmantes sobre as duas maiores cidades do País: no Rio de Janeiro, o número de desabrigados triplicou em três anos - passou de cinco mil, em 2013, para quase 15 mil em 2016. E, enquanto a população do município de São Paulo cresce, em média, 0,7\% ao ano, o número de sem-teto aumenta 4,1\% - contabilizando em 2017 aproximadamente 25 mil cidadãos sem domicílio. Grande parte desse percentual é de trabalhadores que não se alinha com o 'perfil tradicional' de 'morador de rua, sujo, maltrapilho e desocupado', que circula no imaginário social.

O Instituto de Pesquisa Econômica Aplicada (Ipea) ${ }^{3}$ estimou que, em 2015, existiam 101.854 pessoas em situação de rua no Brasil. Deste total, 40.741 pessoas $(40,1 \%)$ viviam em municípios com mais de 900 mil habitantes e mais de 78 mil pessoas $(77,02 \%)$ em municípios de grande porte, com mais de 100 mil habitantes. No Rio de Janeiro, a Secretaria Municipal de Assistência Social e Direitos Humanos (Smasdh) ${ }^{4}$ registra que, atualmente, 15 mil pessoas vivem nas ruas, número três vezes maior que em 2013. Perante esse quadro, lançamos a seguinte provocação: Qual o comportamento da imprensa diante dessas pessoas?

Com base em reflexões a respeito dos Direitos Humanos, da Cidadania e sobre as noções de Igualdade e Diferença, analisamos uma amostra de reportagens sobre este fenômeno social que aflige o país. Nossa atenção se concentrou na capital carioca, com o foco especial na população em situação de rua. Este esforço nos proporcionou a oportunidade para discutir as práticas jornalísticas frente a questões sociais emergentes.

\section{DE QUE POPULAÇÃO ESTAMOS FALANDO?}

Em pesquisa realizada por uma das coautoras deste trabalho ${ }^{5}$, além da preocupação mais ampla com a população em situação de rua, chama à atenção a mulher enquanto personagem emblemática desse grupo social. Constatamos que embora famílias inteiras estejam fazendo dos espaços públicos moradia, a quantidade de mulheres adultas em situação de rua (18\%) é, de modo geral, inferior a de homens na mesma condição (82\%).

\footnotetext{
${ }^{2}$ Disponível em: http://g1.globo.com/profissao-reporter/noticia/2017/07/cresce-o-numero-de-moradores-de-ruaem-sao-paulo-e-no-rio-de-janeiro.html

${ }^{3}$ Disponível em: http://www.ipea.gov.br/portal/images/stories/PDFs/TDs/26102016td_2246.pdf

${ }^{4}$ Disponível em: http://www.rio.rj.gov.br/web/guest/exibeconteudo?id=6982189

${ }^{5}$ BORTOLI, Suzana Rozendo. Mulheres adultas em situação de rua e a mídia. Tese. São Paulo: ECA/USP, 2017.
} 
Nesse momento, portanto, é importante explicitar que as mulheres em situação de rua são aquelas despossuídas de um imóvel próprio, alugado ou emprestado; que utilizam o espaço público como abrigo, eventual ou constantemente; mulheres sem ou com frágeis vínculos familiares (de modo que nenhum parente aceite conviver com elas na mesma residência ou fornecer nenhum tipo de amparo); que necessitam de assistência social ou ajuda de caridade para se alimentar, dormir e se higienizar; que pernoitam em albergues, abrigos, hotéis, pensões, repúblicas ou casas de convivência; pessoas descomprometidas com os deveres do cidadão e desamparadas quanto aos seus direitos (FRAZÃO, 2010); que, na rua, convivem com a indiferença, a discriminação e o desprezo; que passam despercebidas, mesmo estando bem visíveis (TIENE, 2004). São mulheres discriminadas ou, muitas vezes, perseguidas, com baixo poder de expressão e representação política (DANTAS, 2007).

Escorel (1999) define o espaço do lar como um ambiente que envolve domesticidade, intimidade e privacidade. Desprovidas de um 'lar', a população de rua feminina tem suas peculiaridades e enfrenta maiores dificuldades. Fatores biológicos como menstruação, gravidez, filhos e fragilidade física, e também questões sociais, como o moralismo e as expectativas sobre a mulher, representam, para elas, grandes frustrações.

Os motivos pelos quais algumas mulheres passam a viver nas ruas englobam desde drogadição, adoecimento, dívidas, desastres ambientais, incêndios residenciais, perda de emprego, brigas familiares, violência doméstica, valorização imobiliária, doenças, problemas de mobilidade urbana, falecimento do provedor da casa, desintegração familiar por morte, desentendimentos com milicianos e/ou traficantes, etc.

Afastadas de seu ambiente de origem, essas mulheres carregam consigo poucos pertences. Além da dificuldade de carregar peso, Escorel (1999) adverte que o acúmulo de materiais aumenta a visibilidade, "portanto, a repressão tanto dos órgãos públicos quanto dos moradores com teto na localidade" (ESCOREL, 1999, p. 223).

As pessoas sem renda conseguem arrecadar algum dinheiro através da reciclagem ou, até mesmo, da mendicância. Dentre as inúmeras dificuldades da vida nas ruas, a falta de endereço físico, muitas vezes, torna-se um impeditivo na tentativa ou busca de emprego fixo.

Estar ou ficar doente é um fator recorrente para essas pessoas. Rosa e Brêtas (2015) mencionam um estudo realizado no Canadá sobre o risco de morte entre mulheres em situação de rua: "essas mulheres, entre 18 e 44 anos de idade, têm entre oito e trinta vezes mais chances de morrer do que as mulheres da mesma faixa etária da população em geral" (ROSA, BRÊTAS, 2015, p.276), sobretudo pela dificuldade do acesso a tratamento de saúde. As 
doenças mais comuns são problemas nos pés, por passarem muitas horas por dia em pé nas ruas ou andando; infestações pela dificuldade de acesso a locais para higiene pessoal; Doenças Sexualmente Transmissíveis, como sífilis e herpes e HIV, tuberculose e doenças crônicas, como hipertensão e diabetes (BRASIL, 2012).

É bem comum a associação imediata entre o alcoolismo e a vida nas ruas. Brognoli (1996) cita que o álcool vai além de um vício: atua como suporte de vida cotidiana em público, serve para reduzir a inibição na hora de pedir dinheiro, 'anestesia' o frio, a fome, as dores físicas e as lembranças ruins, além de ser um reforçador dos laços interpessoais flutuantes. Em seus estudos, Camila Giorgetti (2006) observou que, no Brasil, os médicos mostram o alcoolismo como fator desencadeante do processo que conduz às ruas, responsabilizando, desse modo, o próprio indivíduo. Ao passo que na França, os médicos não mencionam o alcoolismo como causa desse processo, mas sim o desemprego e a ruptura familiar. É importante ainda mencionar que grande parte das mulheres em situação de rua que sofrem de alcoolismo possui histórico familiar do problema, como se o envolvimento com o álcool fosse um hábito incutido desde muito antes de viverem nas ruas.

A violência se manifesta de diversas maneiras no cotidiano dessas mulheres: a violência praticada por pessoas ou grupos intolerantes com a situação de pobreza; a violência entre as próprias pessoas que se encontram na rua (brigas por dívidas de drogas, disputa de espaço, furtos, desavenças e infidelidade conjugal); a violência planejada, cometida por seguranças contratados por comerciantes ou moradores que se sentem prejudicados pela presença dos sem-teto próximos de seu comércio ou de sua residência; a violência sexual praticada por homens, em situação de rua ou não, “com potencial de causar danos físicos e mentais irreparáveis na mulher" (ROSA; BRÊTAS, 2015, p.279); a violência manifestada em forma de preconceito e discriminação.

As mulheres em situação de rua, quando assim identificadas, muitas vezes, são impedidas de entrar em estabelecimentos comerciais ou restaurantes (mesmo que tenham dinheiro para adquirir o que precisam) ou são expulsas de locais com grande circulação de turistas por serem associadas a uma espécie de degradação do ambiente. Gisele Arrunátegui Gadf (2008) afirma que a mulher é discriminada até mesmo pelos homens sem-teto, que acreditam que elas estão nesta condição por opção, por acomodação, por facilidades devido à suposta fragilidade feminina, sendo mais vulneráveis à 'degeneração', pela prostituição e uso de drogas. 
Algumas mulheres preferem circular em grupos ou sozinhas pelas vias públicas. De acordo com Escorel, o isolamento não emerge como uma contraposição aos agrupamentos: "o 'bloco do eu sozinho' prevalece como recurso para amenizar conflitos e como estratégia para diminuir a visibilidade e, portanto, a repressão" (ESCOREL, 1999, p. 165). Outras, porém, têm a necessidade de um 'companheiro' como 'escudo de proteção' e precisam 'pagar' por isso.

Não é cena rara encontrar uma mulher em situação de rua se portando como louca ou como se fosse um homem. Lopes, Borda e Reis (2003) indicam que alguns comportamentos considerados sintomáticos, como o de 'loucura', podem ser um mecanismo de proteção contra a violência sexual e a física.

Nas grandes metrópoles brasileiras, faltam vagas nos abrigos públicos e nas unidades de reinserção social para atender a demanda. Quando não, as regras desses estabelecimentos são extremamente rigorosas ou o abuso de poder dos funcionários é tão descarado que as mulheres 'optam' pela liberdade da rua, pois não se sentem acolhidas. Tais instituições, reiteradamente, parecem muito mais isolar e punir que de fato reintegrar as usuárias à sociedade e às funções da vida comum.

Enfim, o Estado falha no que se refere às políticas de assistência à mulher em situação de vulnerabilidade, como por exemplo, abrigos temporários em rede com políticas de trabalho e habitação. Muitas mulheres que poderiam estar passando por uma situação passageira ficam continuamente na rua ou dependentes de abrigos públicos por falta de investimento do governo em programas sistêmicos de proteção à mulher, de incentivo ao trabalho, em transporte público e em mobilidade urbana.

Do a situação particular - mulher - partimos a seguir para o contexto mais amplo da população de rua, promovendo um debate sobre os diretos à cidadania e sobre igualdade e diferença.

\section{CIDADANIA, IGUALDADE E DIFERENÇA}

A errância que caracteriza a situação de rua sempre esteve presente nas cidades, desde o mundo antigo. Em todas as épocas, esse fenômeno foi provocado por uma combinação de fatores: econômicos, políticos e sociais (FRANGELLA, 2004). De acordo com a autora, a partir da Idade Média, esse público passa a viver em volta dos feudos e buscar ajuda da igreja. 
Já nesse período, começam a ser classificados como vagabundos, mendigos, migrantes, incapacitados, sem domicílio fixo.

Para Maria Lucia Lopes da Silva (2009) o fenômeno remonta ao surgimento das sociedades pré-industriais da Europa, quando os camponeses foram desapropriados de suas terras sem que as indústrias das cidades os absorvessem com a mesma amplitude. Isso gerou um 'exército industrial de reserva'.

Michel Foucault destaca que o Século XVII criou vastas casas de internamento, onde um em cada cem habitantes de Paris passou por alguns meses. Em 1656, um decreto instituiu o Hospital Geral para o qual foram destinados os pobres de Paris, fossem eles "de todos os sexos, lugares e idades, de qualquer qualidade de nascimento, e seja qual for sua condição, válidos ou inválidas, doentes ou convalescentes, curáveis ou incuráveis" (FOUCAULT, 2000, p. 49). Como salienta o autor, tratava-se "de recolher, alojar, alimentar aqueles que se apresentam de espontânea vontade, ou aqueles que para lá são encaminhados pela autoridade real ou judiciária” (Ibidem, p.49). Em outros termos, o 'recolhimento' de pobres das ruas já visava um processo conhecido até nossos dias como higienização das cidades.

No Brasil, a população de rua passou a ser reconhecida como um problema de saúde pública com a chegada da Coroa Portuguesa no século XIX. Políticas de higienização dos espaços urbanos iriam estratificar esse público, inserindo-o em instituições especializadas, como orfanatos, hospícios, asilos de velhos e prisões (COSTA, 1989).

Este histórico empenho para tirar pobres, desocupados, desviantes das ruas advém de linhas imaginárias estabelecidas na Modernidade. Como ressalta Boaventura de Sousa Santos,

O pensamento moderno ocidental é um pensamento abissal. Consiste num sistema de distinções visíveis e invisíveis, sendo que as invisíveis fundamentam as visíveis. As distinções invisíveis são estabelecidas através de linhas radicais que dividem a realidade social em dois universos distintos: o universo 'deste lado da linha' e o universo 'do outro lado da linha'. A divisão é tal que 'o outro lado da linha' desaparece enquanto realidade, torna-se inexistente, e é mesmo produzido como inexistente (SANTOS, 2009, p. 2324).

Para o autor, o pensamento abissal moderno salienta-se pela sua capacidade de produzir e radicalizar distinções. Tal visão se tornou mais evidente na Modernidade porque ali se desenvolveu o que chama de 'razão indolente'. Santos (2002) sublinha que esta razão subjaz, nas suas várias formas, ao conhecimento hegemônico, tanto filosófico como científico, produzido no Ocidente nos últimos duzentos anos. Uma de suas variações é a que nomeia 
como 'razão metonímica', a qual é obcecada pela ideia da totalidade sob a forma da ordem. A arrogância dessa razão está em atribuir ao todo o que é característica de uma das partes. Esta promove uma totalidade em forma de dicotomia e de hierarquização, como "cultura científica/cultura literária; conhecimento científico/conhecimento tradicional; homem/ mulher; cultura/natureza; civilizado/primitivo; capital/trabalho; branco/negro; Norte/Sul; Ocidente/Oriente [...]" (SANTOS, 2002, p. 242).

Dessa maneira, aqueles que não se enquadram no padrão estabelecido pela totalidade imaginada - que também estão 'do outro lado da linha abissal' - são invisíveis, porque esta indolência gera a não-existência. Se invisíveis e não-existentes, como é o caso da população em situação de rua, lhes são negados não só seu direito de existir, como seus direitos de cidadãos.

Em seus estudos sobre Cidadania, José Murilo de Carvalho (2015) observa que se tornou costume desdobrar a cidadania em direitos civis, políticos e sociais. "O cidadão pleno seria aquele que fosse titular dos três direitos. Cidadãos incompletos seriam os que possuem apenas alguns direitos. Os que não se beneficiam de nenhum dos direitos seriam não cidadãos" (CARVALHO, 2015, p. 15). Segundo o autor, os direitos civis são os fundamentais como vida, liberdade, propriedade, igualdade perante a lei. Os direitos políticos se referem à participação no governo da sociedade; consiste na capacidade de fazer demonstrações políticas, de organizar partidos, de votar e ser votado. Já os direitos sociais garantem a participação na riqueza coletiva, incluindo educação, trabalho, salário justo, saúde, habitação. "Os direitos sociais permitem às sociedades politicamente organizadas reduzir os excessos de desigualdade produzidos pelo capitalismo e garantir um mínimo de bem-estar para todos. A ideia central em que se baseiam é a da justiça social", assevera o autor (Ibidem, p. 16).

Ao versar sobre os Direitos Humanos, Santos (1997) assinala que a Modernidade gerou algumas tensões dialéticas. As tensões entre emancipação social e regulação social, e entre Estado e sociedade civil tiveram como cerne os direitos humanos. Dali surgem as principais conquistas da população, o que pressupõe que o Estado é o principal provedor dos direitos humanos.

O Estado-providência, como adverte Santos (1997), tem se demonstrado incapaz de acolher minimamente esta população. A estrutura e as políticas públicas deste modelo parecem ser insuficientes para o seu atendimento adequado, o que tem levado os movimentos sociais a assumirem grande parcela desse desafio. 
Entre os trinta artigos da Declaração Universal dos Direitos Humanos ${ }^{6}$, destacamos um deles:

\begin{abstract}
Artigo XXV
1. Toda pessoa tem direito a um padrão de vida capaz de assegurar a si e a sua família saúde e bem estar, inclusive alimentação, vestuário, habitação, cuidados médicos e os serviços sociais indispensáveis, e direito à segurança em caso de desemprego, doença, invalidez, viuvez, velhice ou outros casos de perda dos meios de subsistência fora de seu controle.
\end{abstract}

Diante desse quadro, a mulher em situação de rua, como já contextualizada neste trabalho, encontra-se 'do outro lado da linha abissal' por vários motivos aqui discutidos. Está marginalizada, a começar, por uma questão de gênero, na distinção sociocultural construída homem/mulher; por estar em situação de vulnerabilidade social; por não possuir moradia e/ou depender de ajuda para alojar-se, alimentar-se. Ainda que grande número delas tenha seus documentos - carteira de identidade, título de eleitor - e sintam-se cidadãs, lhes são negados muitos de seus direitos sociais como os contemplados neste artigo da DUDH. São cidadãs incompletas, como sugere Carvalho?

Santos nos lembra que, na Modernidade, a igualdade, a liberdade e a cidadania foram reconhecidos como princípios emancipatórios da vida social. O autor frisa, no entanto, outro conflito gerado naquele momento, qual seja, entre o ideário de emancipação e os interesses burgueses com o desenvolvimento capitalista. Dessas tensões, acentuaram a desigualdade e a exclusão. Assim, “a desigualdade é um fenómeno socioeconômico, a exclusão é, sobretudo, um fenómeno cultural e social, um fenómeno da civilização. Trata-se de um processo histórico através do qual uma cultura, por via de um discurso de verdade, cria o interdito e o rejeita" (SANTOS, 1995, p.2). No seu entender, o Estado tem fracassado na gestão dos processos de exclusão. Esta gestão se dá por via da assimilação seguida de uma política cultural orientada para a homogeneização e a homogeneidade. Por isso mesmo, nenhuma das políticas colocadas em prática tentou eliminar a exclusão, mas fizeram apenas sua gestão controlada. Tratou-se de diferenciar entre as diferenças. Por fim, Santos assegura "que os grupos sociais por elas atingidos foram transferidos do sistema de exclusão para o sistema de desigualdade" (SANTOS, 1995, p. 18-19).

Vitimadas pela desigualdade social e excluídas historicamente por uma cultura eurocentrista, as mulheres em situação de rua estão impregnadas por estigmas e sujeitas a preconceitos e, por isso mesmo, são discriminadas por grande parcela da população. Se

\footnotetext{
${ }^{6}$ Disponível em: http://www.onu.org.br/img/2014/09/DUDH.pdf
} 
excluídas socialmente, como estas mulheres são tratadas pela imprensa? A imprensa cumpre seu papel de promoção da cidadania, de emancipação social?

\section{A IMPRENSA E A RUA}

Nosso empenho para perceber o tratamento que a imprensa atribui à população de rua observamos uma amostra de reportagens com o apoio da Análise de Conteúdo. Trata-se de um trabalho de análise qualitativa. Segundo Oliveira (2008, p.7), “o pesquisador qualitativo pauta seus estudos na interpretação do mundo real, preocupando-se com o caráter hermenêutico na tarefa de pesquisar sobre a experiência vivida dos seres humanos". Para nos auxiliar nessa empreitada, utilizamos a técnica da Análise de Conteúdo, proposta por Laurence Bardin (1970). Para a autora, o termo se refere a um conjunto de técnicas de análise das mensagens que tem como principal objetivo deduzir conhecimentos sobre a produção e a receptação das comunicações. O método prevê uma pré-análise, exploração do material e tratamento dos resultados. Por se tratar de material escrito, a Análise de Conteúdo foi compreendida como uma boa técnica para examinar os conotativos e denotativos que produzem sentido nos discursos.

Nosso esforço foi o de mostrar como um receptor receberia a mensagem da forma como apresentada pelos sites e, também, outros modos de absorver ou enxergar tal conteúdo. O objeto empírico é composto por reportagens publicadas pelos jornais online Extra e $O$ Globo no período 2008-2016. Na pré-análise do conteúdo, buscamos matérias de representatividade, homogeneidade e pertinência e exclusividade do tema proposto. Na fase de exploração do material, não utilizamos colunas de classificação neste artigo, por delimitação de espaço. O tratamento dos resultados (inferência e interpretação - terceira fase da $\mathrm{AC}$ ) evidencia o sentido da mensagem que se encontra por trás do apresentado pelo autor do texto.

Como primeira constatação, pudemos observar que em grande parte do material as narrativas constroem a ideia de que existe uma nítida associação entre morar na rua e uma vida de perversão. Vejamos a nota a seguir: 
O GLOBO (10 jul 2014)

\section{Ordem Pública apreende 36 pedras de crack no Aterro do Flamengo}

RIO - Agentes da Secretaria municipal de Ordem Pública (Seop) apreenderam, nesta terça-feira, 36 pedras de crack no Aterro do Flamengo, nas proximidades do Museu de Arte Moderna (MAM). De acordo com a polícia, a droga era utilizada por moradores de rua, que deixaram o local após a chegada da equipe de fiscalização. O material foi encaminhado para a $10^{\circ} \mathrm{DP}$ (Botafogo).

(Figura1)

Ora, se as pessoas deixaram o local, como os policiais sabiam que elas moravam nas ruas? Afirmaram isso apenas com base na aparência física? Seria possível que residiam em casas na região e estavam ali apenas consumindo a droga? Uma pesquisa realizada na rede estadual de acolhimento no Rio de Janeiro mostrou que quase $80 \%$ dos usuários de crack tinham casa e família ${ }^{7}$, entretanto, ficou evidente neste registro jornalístico a associação entre consumo de drogas e os desabrigados. Mesmo um leitor mais atento, dificilmente poderia questionar a veridicidade desta informação, pois tal estereótipo já está bastante arraigado na nossa cultura.

Outra característica mapeada é a associação entre viver nas ruas e praticar crimes, como mostra já o primeiro parágrafo desta notícia:

\footnotetext{
${ }^{7}$ Disponível em: http://g1.globo.com/rio-de-janeiro/noticia/2015/05/pesquisa-diz-que-79-dos-usuarios-de-crackdo-rj-nao-moram-nas-ruas.html . Acesso em: 13 out. 2015.
} 


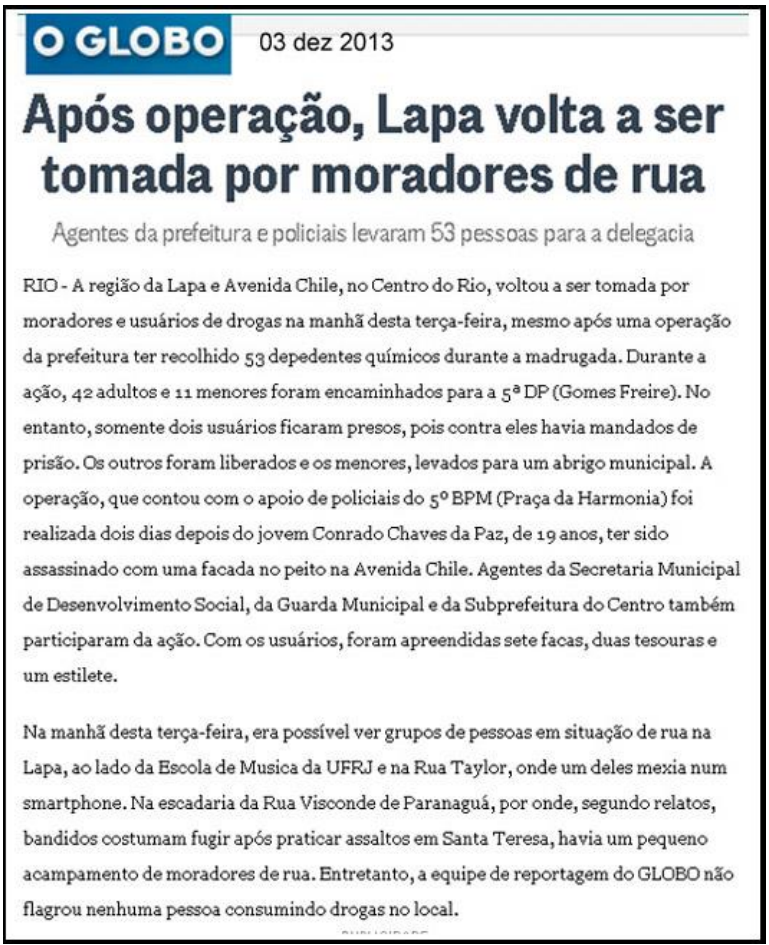

(Figura 2)

Note-se que na última frase, a matéria evidencia até mesmo um sentimento de inconformismo por apenas dois envolvidos serem presos. Mais adiante, o repórter conduz o leitor a pensar que aquelas pessoas, possivelmente, cometiam assaltos. O último parágrafo é fechado externando um sentimento de descontentamento, desta vez por não ter sido registrado um flagrante de uso de drogas entre os noticiados. O título dessa outra reportagem do jornal Extra é autoexplicativo: 


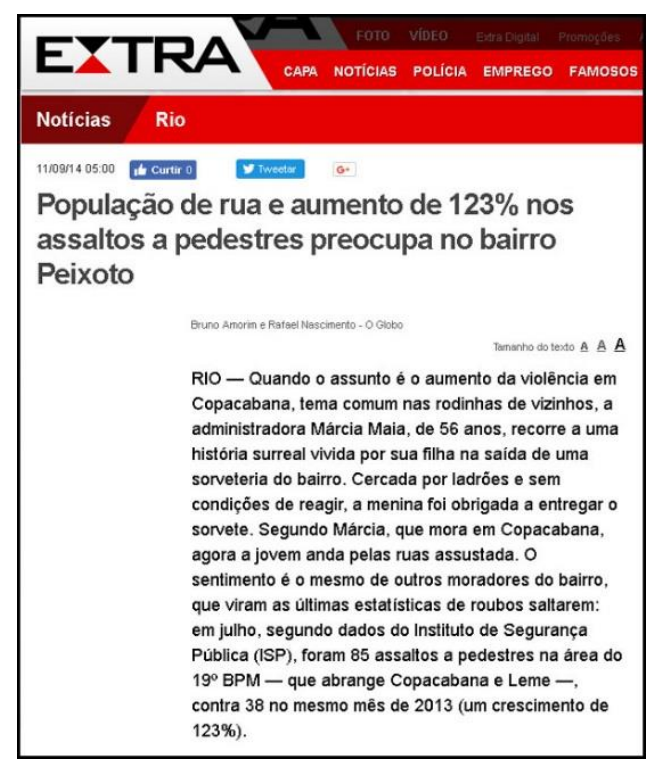

(Figura 3)

Algumas notícias vinculam a degradação dos espaços públicos com a existência de pessoas dormindo nesses locais e consumindo drogas:

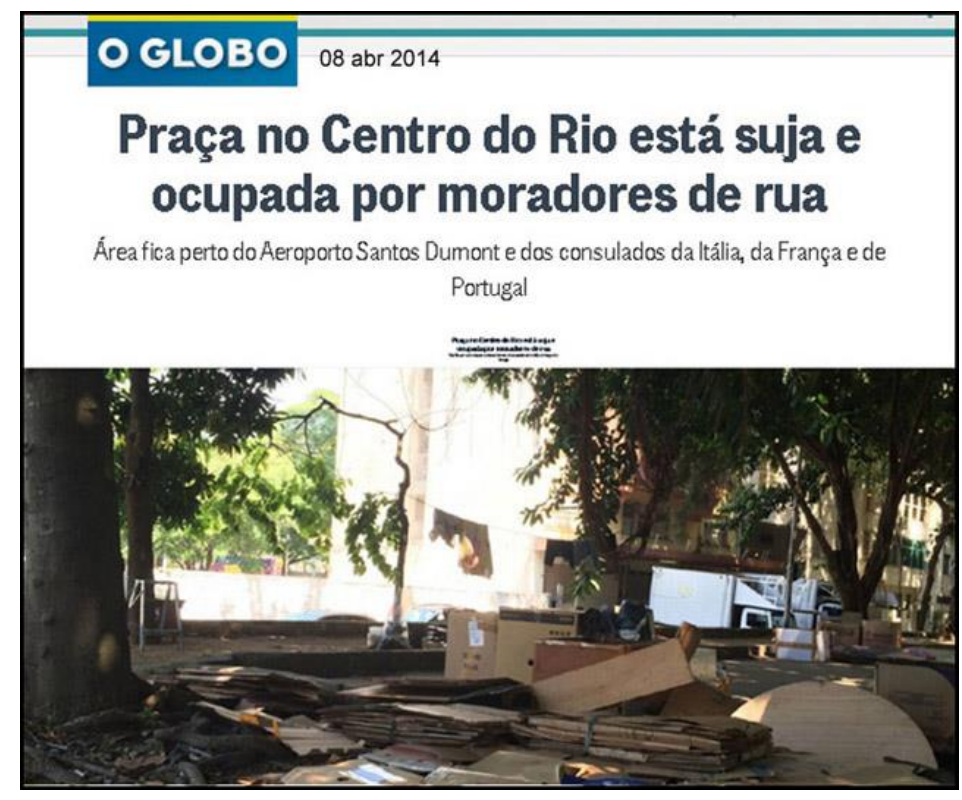

(Figura 4)

O início da matéria já denota o preconceito: “A Praça Virgílio de Melo Franco, no Centro do Rio, está abandonada. Sem conservação, o local passou a ser ponto de parada de moradores de rua e usuários de crack, segundo o leitor Leno Oliveira”. Importante mencionar que as fontes ouvidas para a reportagem foram: um leitor, a Comlurb (empresa de limpeza urbana) e a Secretaria de Desenvolvimento Social. Nenhum representante de Fórum, ONG ou movimento social da população em situação de rua teve voz nessa notícia. 
Outro ponto que merece destaque é a ideia de ter que recolher e levar quem vive nas ruas para abrigos municipais. De 2010 a 2015, notas com conteúdos similares sobre essa prática foram exaustivamente publicadas:

Choque de Ordem na Zona Sul acolhe 50 moradores de rua na madrugada (26/05/2010);

Choque de Ordem retira 109 moradores de rua na Zona Sul (23/06/2010);

Operação Choque de Ordem recolhe moradores de rua na Central do Brasil $(04 / 11 / 2010)$;

Choque de Ordem apreende mercadorias e recolhe moradores de rua na Glória (29/08/2010).

Nenhuma delas questionou as condições dos abrigos para os quais os sem-teto foram 'acolhidos' ou 'recolhidos'. As notícias específicas sobre mulheres em situação de rua, basicamente, estão restritas a assuntos que envolvem algum tipo de violência, a exemplo desta, de 2007, divulgada no jornal Extra online.

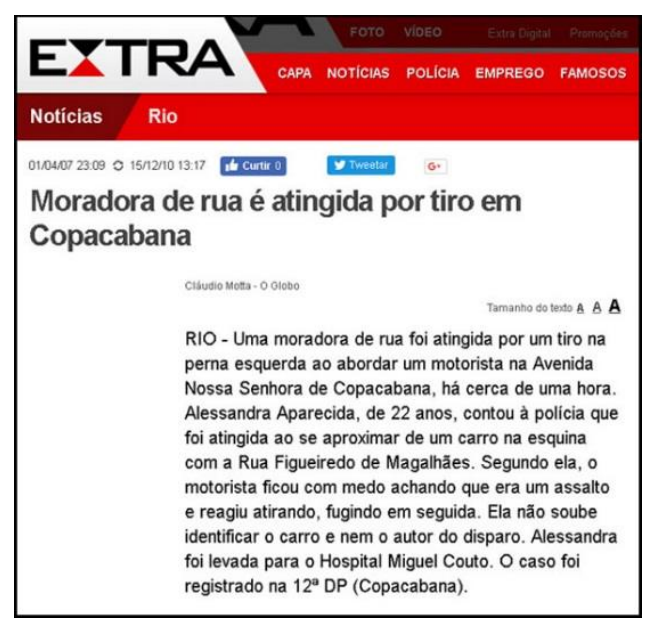

(Figura 5)

Importante destacar que antes de sabermos que a vítima é Alessandra Aparecida, ela é denominada moradora de rua, como se a condição fosse um 'cargo' que devesse anteceder o nome. Sublinhamos que a mulher foi atingida por um tiro porque o motorista ficou com medo achando que era um assalto, e nenhum texto foi adicionado em seguida, como se já fosse natural que uma pessoa com 'aparência de rua' fosse cometer um delito.

Em 2014, o jornal Extra divulgou uma nota sobre o parto de Cristiane Carneiro da Silva, feito em uma calçada pelos bombeiros. O relato não informa sequer o destino da criança. 


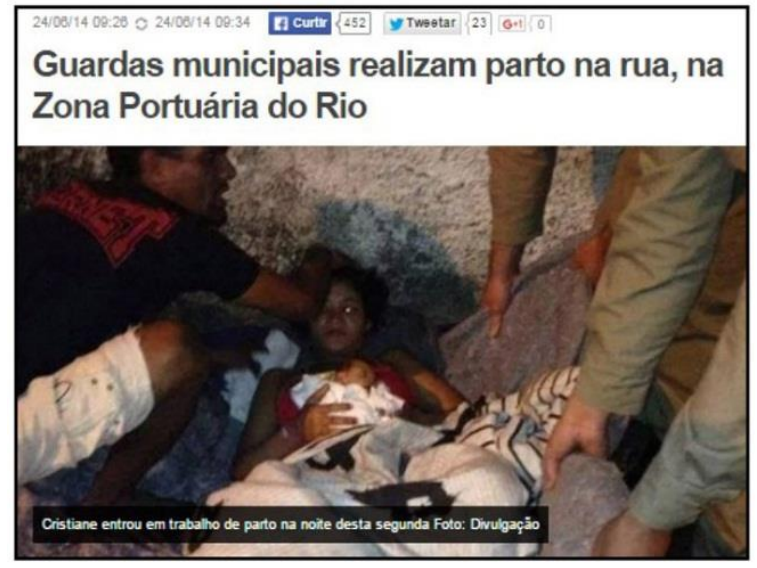

(Figura 6)

Esta outra notícia, de 2015, publicada no site $O$ Globo, "Agentes da prefeitura derrubam barraco de papelão em calçada da Presidente Vargas”, mostra a ação da Secretaria municipal de Ordem Pública (Seop) destruindo a casa construída em uma calçada no centro da cidade por Shirley da Conceição Andrade e Silva Barros.

Sem qualquer repressão, ela ergueu seu barraco na calçada da via, na esquina com a Rua Uruguaiana. E até já havia pintado a "casa" de branco, em pleno coração financeiro do Centro. Durante a ação, que não foi acompanhada por assistentes sociais da prefeitura, Shirley ficou descontrolada. De acordo com os agentes, ela não quis ir para qualquer abrigo. A equipe chegou a chamar o Corpo de Bombeiros para tentar acalmar a moradora de rua.

O Globo, 3 abr 2016

A mulher ergueu o barraco com papelão e madeira e, no meio da calçada, reproduziu os cômodos de uma casa: "Um pouco afastado do cômodo principal, próximo à pilastra de concreto do prédio de uma grande agência bancária, ficava o banheiro: pequeno e cercado de papelão. Dentro, num varal, havia roupas íntimas penduradas". Mas sua presença e sua 'sujeira' incomodavam os comerciantes da região, as pessoas que passavam pelo local ou que almoçavam nos restaurantes da redondeza. Sem complexificar a contradição, a notícia traz, ainda, informações que Shirley, mesmo a contragosto, foi 'recolhida' enquanto vagava pelo Centro e levada para um centro de acolhimento. As únicas fontes ouvidas foram agentes da Secretaria de Ordem Pública.

Como se pode constatar por esta amostra de matérias, há evidentes problemas de apuração, uma vez que a grande maioria parece ter sido pautada e redigida a partir de boletins de ocorrências e com poucas evidências de investigação. $\mathrm{O}$ repórter foi à rua? Além de os textos serem escritos de maneira crua, nota-se pouca ou nenhuma preocupação com a contextualização de cada caso. Estas questões técnicas, integradas a uma postura acrítica e 
preconceituosa de jornalistas e editores, fazem prevalecer nas narrativas o grotesco, beirando ao sensacional. Enfim, os órgãos de imprensa examinados denotam estarem despreocupados (e desobrigados) de seu compromisso social de atuar para a emancipação social, de contribuir para a cidadania - de todos e para todos.

\subsection{Caminhos alternativos são possíveis}

Em matéria publicada pelo jornal Valor Econômico ${ }^{8}$, em janeiro de 2017, a jornalista Lígia Guimarães reporta o morar na rua como fenômeno que atinge cada vez mais famílias, e não apenas homens ou mulheres como indivíduos. Percebe-se no texto o respeito às pessoas e preocupação com a contextualização, como no trecho a seguir:

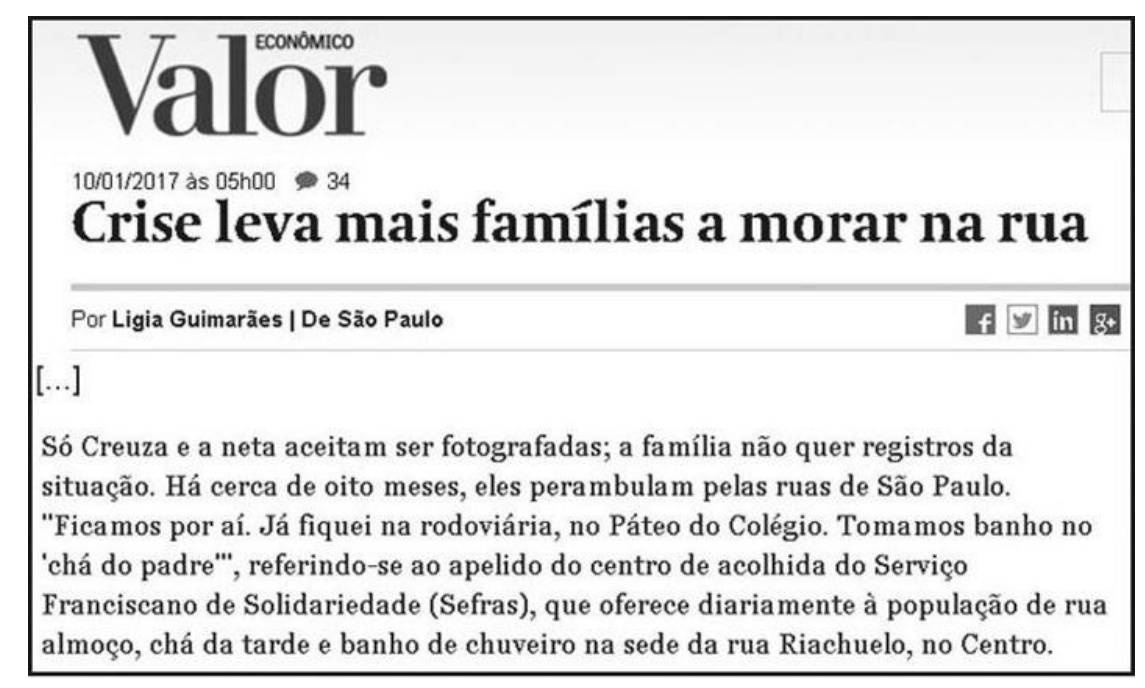

(Figura 7)

Ao explorar o site do Observatório de Defesa dos Direitos e Bens Comuns, da ABONG (Associação Brasileira das Organizações não Governamentais), temos outra perspectiva sobre o movimento das pessoas em situação de rua, e das mulheres em situação de rua ao destacar a participação de Maria Lúcia Pereira da Silva:

\footnotetext{
${ }^{8}$ Disponível em: http://www.valor.com.br/brasil/4831060/crise-leva-mais-familias-morar-na-rua
} 
$[\ldots]$

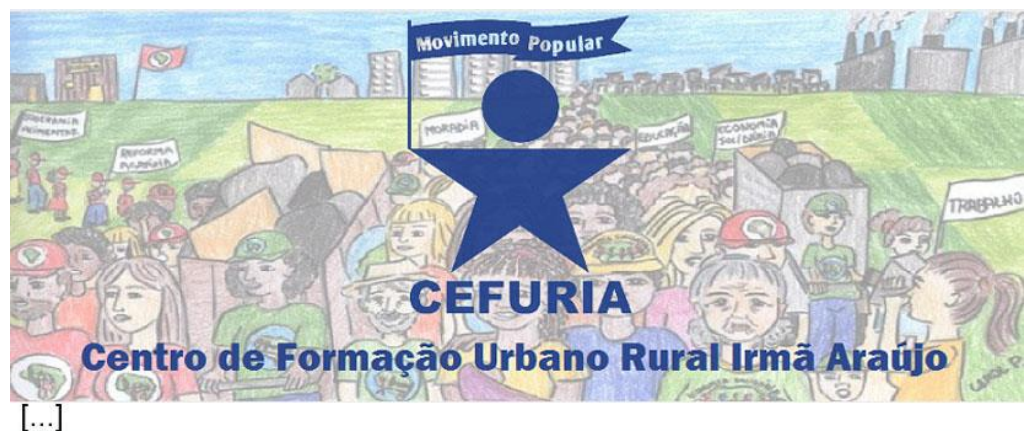

"Se vocês tivessem me encontrado há 16 anos, não dariam nada pela minha vida. Hoje eu estou aqui, na ONU"

(1) Publicado em 4 de março de 2016 Faça um comentário

Em Genebra, Coordenadora do Movimento Nacional da População em Situação de Rua, Maria Lucia Pereira da Silva avaliounesta sexta-feira (4) relatório especial de moradia adequada do Conselho de Direitos Humanos da ONU.

(Figura 8)

O trabalho do Observatório da $\mathrm{ABONG}^{9}$ relata o fato e oferece links sobre quem é a personagem da notícia. Há vídeos que narram a história de vida de Maria Lúcia, seu depoimento e dos seus companheiros e companheiras de jornada. O crédito ao trabalho é da Cefuria $^{10}$. A organização se apresenta em seu site desta maneira:

O que é o CEFURIA?
A palavra CEFURIA é a sigla ou nome fantasia do Centro de Formação Urbano Rural Irmã
Araújo. Uma organização da sociedade civil, sem fins lucrativos, cuja finalidade é
fortalecer a organização popular e as lutas do povo por melhores condições de vida. Seu
nome é uma homenagem à Irmã Araújo, cuja vida foi dedicada à organização dos pobres
da região sul de Curitiba para resolução de seus problemas concretos, principalmente
aqueles relacionados à saúde.
como resultado dessas lutas, conquistas importantes aconteceram nos anos 80 , tais
como postos de saúde nos bairros, solução para problemas de enchentes, relocação de
moradias para áreas com menores riscos, melhoria do transporte coletivo, etc.

(Figura 9)

Vimos que o texto produzido pela ABONG tem as qualificações jornalísticas para contextualizar reportagens sobre mulheres em situação de rua. E, lendo com atenção a matéria do Valor Econômico, percebemos que o texto escrito pela Cefuria permite construir uma hipótese de investigação jornalística sobre a importância de apoiar políticas públicas que

\footnotetext{
${ }^{9}$ Disponível em: https://observatoriosc.wordpress.com/2016/03/17/se-voces-tivessem-me-encontrado-ha-16anos-nao-dariam-nada-pela-minha-vida-hoje-eu-estou-aqui-na-onu/\#respond

${ }^{10}$ Ver: http://www.cefuria.org.br/quem-somos/
} 
trabalhem com a população em situação de rua, investindo no desenvolvimento de suas capacidades como seres humanos.

\section{CONSIDERAÇÕES}

O Jornalismo contemporâneo teve suas bases estabelecidas nos Século XIX, sob os influxos do pensamento científico moderno. Como nos lembra Cremilda Medina, "Naquele período, se propõe gramáticas presentes tanto na metodologia da pesquisa do conhecimento científico quanto na de captação e narrativa da contemporaneidade que se difunde nos meios de comunicação social” (MEDINA, 2008, p. 18). Assim, os modelos que praticamos até hoje, configurados fortemente por essas influências, herdaram aspectos extremamente positivos, como o processo de reportagem - que se traduz nas salas de redação em trabalho de apuração e checagem, com ganhos em precisão - como também outros que merecem atenção.

Em sua crítica à ciência moderna, Santos (2010) elucida que a ciência como conhecimento monopolista privilegia uma epistemologia das consequências; estas vêm sempre antes das causas. $\mathrm{O}$ autor também salienta que, pela lógica da ciência moderna, "é necessário reduzir os fatos sociais às suas dimensões externas, observáveis e mensuráveis" (SANTOS, 2010, p. 35). Este foco nas consequências mais que nas causas e transformar fenômenos sociais em coisas - fato-coisa - parecem ser uma postura marcante que a Imprensa assimilou desse pensamento moderno.

No mesmo sentido, Edgar Morin $(2001,2006)$ acredita que desde Descartes, a ciência estabeleceu um paradigma de simplificação, sob o império dos princípios da disjunção e de redução. Fortemente arraigada no Ocidente, esta forma de pensar não percebe a complexidade da natureza, de seus fenômenos. Para o autor, complexidade é um tecido - complexus: o que é tecido junto. Assim, efetivamente é "tecido de acontecimentos, ações, interações, retroações, determinações, acasos, que constituem nosso mundo fenomênico" (MORIN, 2006, p. 13). Desses princípios de disjunção e de redução a que se refere, decorre outro complicador, qual seja, o privilégio de uma ética da explicação, quando acredita ser necessária uma ética da compreensão.

A explicação é caracterizada por seu objetivismo; em contraposição, a compreensão precisa recorrer sempre a um processo de empatia, a um processo subjetivo. A explicação permite conhecer um fato humano (sujeito) como objeto; a compreensão permite compreender um sujeito enquanto sujeito (MORIN, 2001, p. 126). 
Ora, como as mulheres em situação de rua foram tratadas nas reportagens aqui discutidas? Primeiro, as personagens foram construídas por suas aparências - dimensões externas, observáveis e mensuráveis -, como também suas ações foram descritas com base em estigmas socialmente construídos - redução. Os textos explicam 'fatos isolados' de maneira simplista, sem qualquer esforço de compreensão sobre os sujeitos envolvidos naqueles acontecimentos. Por fim, o tema mulher em situação de rua em si tem sido abordado sem qualquer contextualização, ou seja, o fenômeno do crescimento da população de rua é tratado como causa de males da vida urbana. A rigor, não é causa, mas consequência decorrente de muitos outros fatores - econômicos, políticos, sociais.

Por esta reflexão, devemos inferir que setores conservadores da Imprensa, ao invés de "defender os direitos do ser humano", como se comprometem em seu Código de Ética e Autorregulação da $\mathrm{ANJ}^{11}$, reforçam estereótipos e preconceitos. Seus repórteres e editores, ao manterem essa postura, desdenham artigos valiosos do Código de Ética dos Jornalistas Brasileiros $^{12}$ que, supostamente, prometem cumprir ao assumirem suas funções (Art. 6 - $§$ e $\S \mathrm{XI})$. Por isso mesmo, desprezam qualquer compromisso como profissionais com a sociedade.

O sociólogo francês Alain Touraine (1998) faz uma discussão relevante sobre Igualdade e Diversidade. Quando versa sobre o Outro, defende que não basta identificar, reconhecer e respeitar o Outro, mas é necessário comunicar-se com o Outro. Sobre a mesma preocupação, Boaventura de Sousa Santos acentua que "temos o direito de ser iguais sempre que a diferença nos inferioriza; temos o direito de ser diferentes sempre que a igualdade nos descaracteriza" (SANTOS, 1995, p. 44),

Enquanto grande parcela da população, regida por paradigmas elitistas e uma mentalidade conservadora, não repensar a emergência de comunicar-se com o Outro, de perceber igualdades e diferenças, vamos continuar a demarcar guetos e segregar cada vez mais seres humanos. E muitos jornalistas continuarão a alimentar a intolerância às pessoas desses guetos.

\footnotetext{
${ }^{11}$ Disponível em: http://www.anj.org.br/codigo-de-etica-2/ .

${ }^{12}$ Disponível em: http://fenaj.org.br/wp-content/uploads/2016/01/codigo-de-etica-dos-jornalistas-brasileiros.pdf .
} 


\section{REFERÊNCIAS}

ARRUNÁTEGUI GADF, Gisele Aparecida Dias Franco. Olhares entrecruzados: mulheres em situação de rua na cidade de São Paulo (Tese de Doutorado). São Paulo. Faculdade de Saúde Pública da USP, 2008.

BARDIN, Laurance. Análise de conteúdo. Lisboa: Edições 70, 1970.

BORTOLI, Suzana Rozendo. Mulheres adultas em situação de rua e a mídia: histórias de vida, práticas profissionais com a população de rua e representações jornalísticas. Tese de doutorado. Programa de Pós-graduação em Ciências da Comunicação. ECA/USP, São Paulo, 2017.

BRASIL. Ministério da Saúde. Secretaria de Atenção à Saúde. Departamento de Atenção Básica. Manual sobre o cuidado à saúde junto a população em situação de rua. Brasília: Ministério da Saúde, 2012.

BROGNOLI, Felipe Faria. Trecheiros e pardais: estudo etnográfico de nômades urbanos. 1996. Dissertação (Mestrado em Antropologia Social). Curso de Pós-Graduação em Antropologia Social. Universidade Federal de Santa Catarina, Florianópolis, 1996.

CARVALHO, José Murilo de. Cidadania no Brasil: O longo caminho. 19 ed. Rio de Janeiro: Civilização Brasileira, 2015.

DANTAS, Monica. Construção de políticas públicas para população em situação de rua no município do Rio de Janeiro: Limites, Avanços e Desafios. (Dissertação de mestrado). Fundação Oswaldo Cruz, Rio de Janeiro, 2007.

ESCOREL, Sarah. Vidas ao léu: trajetórias de exclusão social. Rio de Janeiro: Editora FIOCRUZ, 1999.

FOUCAULT, Michel. História da loucura na Idade Clássica. 6 ed. São Paulo: Perspectiva, 2000.

FRAZÃO, Theresa Christina Jardim. O morador de rua e a invisibilidade do sujeito no discurso jornalístico. (Tese de Doutorado) Programa de Pós-Graduação em Linguística. Universidade de Brasília. Brasília, 2010.

GIORGETTI, Camila. Moradores de rua: uma questão social. São Paulo: Fapesp, Educ, 2006.

LOPES, Roseli; BORBA, Patrícia; REIS, Tiy. Um olhar sobre as trajetórias, percursos e histórias de mulheres em situação de rua. In: Cadernos de terapia pcupacional da UFSCar, v. 11, n.1, 2003.

MEDINA, Cremilda. Ciência e jornalismo: Da herança positivista ao diálogo dos afetos. São Paulo: Summus, 2008.

MORIN, Edgar. O desafio humano da comunicação. In: PENA-VEGA, A.; ALMEIDA, C.R.S.; PETRAGLIA, I. (Orgs). Edgar Morin: Ética, cultura e educação. São Paulo: Cortez, 2001.

Introdução ao pensamento complexo. Porto Alegre: Sulina, 2006.

OLIVEIRA, Cristiano. Um apanhado teórico-conceitual sobre a pesquisa qualitativa: tipos, técnicas e características. In: Travessias, v.2, n.3, 2008.

ONU - Declaração Universal dos Direitos Humanos. Disponível em: http://www.onu.org.br/img/2014/09/DUDH.pdf . Acesso em 22 jul 2017.

ROSA, Anderson da Silva; BRÊTAS, Ana Cristina Passarella. A violência na vida de mulheres em situação de rua na cidade de São Paulo. In: Interface: Comunicação, saúde, educação 2015; 19 (53). p. $275-85$.

SANTOS, Boaventura de Sousa. A construção multicultural da igualdade e da diferença. Palestra proferida no VII Congresso Brasileiro de Sociologia. Rio de Janeiro: Instituto de Filosofia e Ciências Sociais da Universidade Federal do Rio de Janeiro, 4 a 6 set 1995. Disponível em: http://www.ces.uc.pt/publicacoes/oficina/135/135.pdf . Acesso em: 22 jul 2017. 
. Por uma concepção multicultural de Direitos Humanos. Revista

Crítica de Ciências Sociais. N. 48, Junho 1997. Disponível em:

http://www.ces.uc.pt/emancipa/research/pt/ft/multicultural.html . Acesso 22 jul 2017.

. Para uma sociologia das ausências e uma sociologia das emergências.

Revista Crítica de Ciências Sociais. N. 63, Outubro 2002: 237-280. Disponível em:

http://rccs.revues.org/1285. Acesso 22 jul 2017.

Para além do Pensamento Abissal: Das linhas globais a uma ecologia de saberes. In: SANTOS, B.S.; MENEZES, M.P. (Orgs). Epistemologias do Sul. 2 ed. Coimbra: Almedina, 2009.

Um discurso sobre as ciências. 7ed. São Paulo: Cortez, 2010.

TIENE, Izalene. Mulher moradora na rua: entre vivências e políticas sociais. Campinas, SP: Editora Alínea, 2004.

TOURAINE, Alain. Igualdade e diversidade: O sujeito democrático. Bauru: Edusc, 1998.

\section{Original recebido em: 10 de setembro de 2018}

Aceito para publicação em: 27 de julho de 2019

Jorge Kanehide Ijuim Jornalista, doutor em Ciências da Comunicação/Jornalismo pela ECA/USP; Professor do Programa de Pós-graduação em Jornalismo Universidade Federal de Santa Catarina - UFSC e-mail: ijuimjor@gmail.com

Alice Mitika Koshiyama Jornalista e bacharel em História pela USP; Doutora em Ciências da Comunicação pela ECA/USP; Professora do Programa de Pós-graduação em Ciências da Comunicação da ECA/USP e-mail: almitika@gmail.com

Suzana Rozendo Bortoli Jornalista graduada pela Universidade Federal de Mato Grosso do Sul; Doutora em Ciências da Comunicação da Escola de Comunicações e Artes da USP e-mail: sukirozendo@hotmail.com

\section{@ $\odot \otimes \bigcirc$}

Esta obra está licenciada com uma Licença

Creative Commons Atribuição-NãoComercial-CompartilhaIgual 4.0 Internacional 